\title{
Trapezius activity of fibromyalgia patients is enhanced in stressful situations, but is similar to healthy controls in a quiet naturalistic setting: a case-control study
}

\author{
Rolf Harald Westgaard ${ }^{1 *}$, Paul Jarle Mork², Håvard Wuttudal Lorås², Roberto Riva ${ }^{3}$ and Ulf Lundberg ${ }^{3,4}$
}

\begin{abstract}
Background: Muscle activity and pain development of fibromyalgia (FM) patients in response to mental stress show inconsistent results, when compared to healthy controls ( $\mathrm{HCs}$ ). A possible reason for the inconsistent results is the large variation in stress exposures in different studies. This study compares muscle responses of FM patients and HCs for different modes and levels of imposed stress, to elucidate features in stress exposures that distinguish stress responses of FM patients from HCs.

Methods: Upper trapezius (clavicular and acromial fibers), deltoid, and biceps surface electromyographic (sEMG) activity was recorded in FM patients $(n=26)$ and $\mathrm{HCs}(n=25)$. Heart rate $(H R)$ was recorded and used as indicator of autonomic activation. Tests included inspiratory breath holding (sympathetic activation procedure), mental stress tests (color-word test and backward counting; $28 \mathrm{~min}$ ), instructed rest prior to stress test (30 min TV watching), and controlled arm movement. sEMG and HR was also recorded during an unrestrained evening stay at a patient hotel. The 5-min period with lowest trapezius muscle activity was determined. Pain (shoulder/neck, low back pain) and perceived tension were scored on VAS scales at the start and the end of the stress test and at bedtime.

Results: Trapezius sEMG responses of FM patients were significantly higher than HCs during sympathetic activation, mental stress, and instructed rest, but similar during arm movement and unrestrained evening activity. HR of FM patients and HCs was similar during mental stress and in the evening, including the 5-min period with lowest trapezius activity. Muscle activity of FM patients during the stress test (with shoulder/neck pain development) and the evening stay (no pain development) was similar.

Conclusions: FM patients show elevated muscle activity (in particular trapezius activity) in situations with imposed stress, including sympathetic activation, and putative anticipatory stress. Muscle activity and HR were similar to HCs in instructed arm movement and in a situation approaching low-stress daily living. Pain development of FM patients during the stress test may be due to activation of several stress-associated physiological systems, and not obviously caused by muscle activity in isolation.
\end{abstract}

Keywords: Stress, Heart rate, Surface electromyography, Sympathetic activity

\footnotetext{
* Correspondence: rolf.westgaard@iot.ntnu.no

${ }^{1}$ Department of Industrial Economics and Technology Management,

Norwegian University of Science and Technology, Trondheim, Norway

Full list of author information is available at the end of the article
} 


\section{Background}

The central nervous system (CNS) is clearly implicated in the pathophysiology of fibromyalgia (FM) [1-6]; however, a peripheral contribution is likely since muscle tender points are integral to the diagnosis [7-9]. Muscle fiber pathology of FM patients has been reported [10]. Consequently, studies have investigated the association between FM and muscle overexertion or motor control features indicating overexertion, but with mixed results [11-14]. Another line of investigation has focused on muscle activity with stress exposure. Many studies have shown muscle activity in response to imposed stress, with trapezius among the most responsive in this respect [15]. A working hypothesis is that FM patients, due to dysregulation of the autonomic system [16-18], may generate more muscle activity and thereby pain in response to stressful influences. Studies in our laboratory have provided results that both support [19] and fail to support [20] this hypothesis. It may further be questionned whether elevated, but low levels of muscle activity in FM patients relative to healthy controls ( $\mathrm{HC})$, observed under strictly controlled laboratory conditions are replicated in situations close to normal living. A challenge with respect to the latter query is to establish a condition whereby habitual, unrestrained activities of the two groups are comparable.

Differences in muscle responses of FM patients to stress exposure may be due to inadvertent differences in conditions in which the experimental stress test was presented. A test condition with relatively mild stress exposure was used in both of the previous studies $[19,20]$, but circumstances such as laboratory environment and instructions to the subjects differed, which may influence responses [21]. Differential responses to stress exposure may depend on the mode and intensity of the stressful experience. Further, heterogeneity of the FM patient population is shown [22-24] and may account for differences in responses in studies based on limited material.

The present study was carried out in the setting of a hospital patient hotel, where subjects stayed overnight. FM patients and HCs were not allowed to leave the hotel, but were otherwise free to move around. This allowed a realistic comparison of upper trapezius activity during unrestrained sedentary conditions, supplementing a sequence of laboratory tests carried out when subjects arrived in the afternoon: tests with relatively high stress exposure, with sympathetic provocation, a test promoting relaxation with minimal body movement, and a test with controlled arm movement.

It was hypothesized that upper trapezius muscle activity is enhanced for FM patients relative to HCs in situations perceived stressful, potentially dependent on stress level and mode, but is similar in low-stress vocational living. The study aimed to examine this hypothesis by comparing trapezius activity of FM patients and HCs in the above listed test conditions and in sedentary living at the patient hotel, including quiet seated activity and an evening meal. In an earlier study, stress-associated trapezius activity was enhanced in the clavicular direction of the muscle, relative to activity in shoulder elevation [25]. The standardized upper trapezius electrode location [26] was therefore supplemented with a second trapezius electrode placed in a clavicular position. Heart rate (HR) was recorded as a marker of an activation response and to indicate autonomic system balance by HR variability (HRV) measures. Deltoid and biceps were included as examples of muscles with lower responses to stress [15]. Pain in shoulder/neck and in low back, and perceived general tension were scored on visual analogue scales (VAS) [27-29]. Subjectively scored variables were used to elucidate any effect of putative heterogeneity of FM patients [24].

\section{Methods}

\section{Participants}

Twenty-six female patients with FM and 25 age-matched ( \pm 3 years) female HCs participated in the study (Table 1 ). The patients were mainly recruited through the local FM association while $\mathrm{HCs}$ were recruited among donors to the hospital blood bank. Inclusion criteria were age between 35 and 64 years. Upon inclusion to the study, eligible FM patients underwent a clinical examination to verify the FM diagnosis as defined by the American College of Rheumatology [30]. Number of years since first symptoms and number of years since confirmed diagnosis were retrieved from each participant's medical record. Patients were excluded if they had: a) cardiorespiratory, cerebrovascular, neurologic, neuromuscular, endocrine, infectious, metabolic, lung, or cancer disease, b) injury that affected function, c) connective tissue disorder, d) tendinitis or capsular affection of the shoulder joint, or e) high blood-pressure (i.e., systolic pressure $>140 \mathrm{mmHg}$

Table 1 Subject characteristics

\begin{tabular}{|c|c|c|}
\hline & FM patients & Controls \\
\hline & $\overline{\text { Mean (SD), range }}$ & $\overline{\text { Mean (SD), range }}$ \\
\hline Age (years) & $51.8(8.5), 38-64$ & $52.4(8.7), 37-64$ \\
\hline Body mass index $\left(\mathrm{kg} / \mathrm{m}^{2}\right)$ & $26.7(5.3), 17.8-38.9$ & $24.6(3.3), 20.5-35.0$ \\
\hline No. of tender points & $15.7(2.2), 11-18$ & Not Addressed \\
\hline Years since diagnosis & $5.5(6.3), 0-26$ & Not Addressed \\
\hline \multirow[t]{2}{*}{ Years since first symptoms } & $11.6(6.8), 3-33$ & Not Addressed \\
\hline & $\%(n)$ & $\%(n)$ \\
\hline Employment fraction $\geq 50 \%$ & $27(7)$ & $88(22)$ \\
\hline Smokers & $27(7)$ & $24(6)$ \\
\hline Exercise ( $\geq 1$ session per week) & $96(25)$ & $88(22)$ \\
\hline
\end{tabular}

Descriptive statistics for demographic and other background variables of the fibromyalgia (FM) patients and the healthy controls. 
or diastolic pressure $>90 \mathrm{mmHg}$ ) or were taking antihypertensive medication. Participants were also excluded if they were taking medication that may interact with neural, vascular, or muscular function or the physiological measurements to be performed (e.g., antidepressants, antiepileptics, $\beta$-blockers). FM patients that used analgesics and/or sleep medicine on a regular basis were instructed to cease medication two days prior to the experiment. The study protocol was approved by the Regional Committee for Ethics in medical research (project no. 4.2005.2728) and all participants signed an informed consent before inclusion. The study was carried out in the premises of a hotel used by outpatients, with easy access to university laboratories. It is part of a comprehensive study including sleep recordings and the collection of samples for cortisol and catecholamine analyses [31-34].

\section{Procedure}

The order and time schedule for data collection is shown in Figure 1. Participants met in the laboratory at around $4.45 \mathrm{pm}$. After mounting the electrophysiological recording equipment, a session consisting of isometric maximal voluntary contractions (MVCs) and four test conditions was performed (Figure 1): a) controlled arm movement test (see below), b) Laboratory relaxation: participants were comfortably seated in an arm chair and watched a cartoon movie for $30 \mathrm{~min}, \mathrm{c}$ ) mental stress: four 6-min periods alternating between the Stroop test [35] and an arithmetic test with backward counting (mean duration $28 \mathrm{~min}$, range $26-29 \mathrm{~min}$ ), and d) activation of the sympathetic system during standing: intrathoracic pressure was increased by maximal inspiration and breath holding with epiglottis closed for $\sim 15 \mathrm{~s}[36,37]$.

In the controlled arm movement test the participants moved either the dominant or non-dominant hand continuously, holding a pen, between three circles forming an equilateral triangle on a horizontal table [38]. The dominant hand moved in clockwise direction and the non-dominant hand in anti-clockwise direction. Circle diameter was $70 \mathrm{~mm}$ in the first trial and $4 \mathrm{~mm}$ in the second trial. Each trial lasted 2 min and a metronome paced the arm movement at 88 beats $/ \mathrm{min}$, i.e., participants were required to set a mark within the circles following the beat of the metronome. In Laboratory relaxation, participants were instructed to relax to the best of their ability. The experimenter that mounted the recording equipment and performed the tests was blinded to the diagnosis of the participants.

After the laboratory session the participants had an evening meal (bread, salad, fruits) at around $8.30 \mathrm{pm}$ and were thereafter free to choose activity (e.g., reading, watching $\mathrm{TV}$, playing solitaire with cards) but were instructed to stay inside the hotel. The participants filled in a short diary with description of evening activities and time period for each activity. Physiological responses were determined for "quiet seated activity" (reading or watching TV), for the evening meal, and for the 5-min period with lowest surface electromyographic (sEMG) activity of upper trapezius.

The participants scored pain level (shoulder/neck, low back), perceived general tension, and perceived stress on a VAS (0-100 $\mathrm{mm}$ ) upon arrival in the laboratory, after Laboratory relaxation, after the mental stress test, and at bedtime (Figure 1). Pain intensity was scored after first indicating whether they at all felt pain (yes/no). All VAS scales were anchored by "very high" and "very low" at endpoints. Participants also scored their level of effort associated with the stress test and how stressful they perceived the test.

\section{Physiological recordings and analysis}

A portable recording system (Myomonitor IV, Delsys Inc, Boston MA) was used to record force, sEMG, a
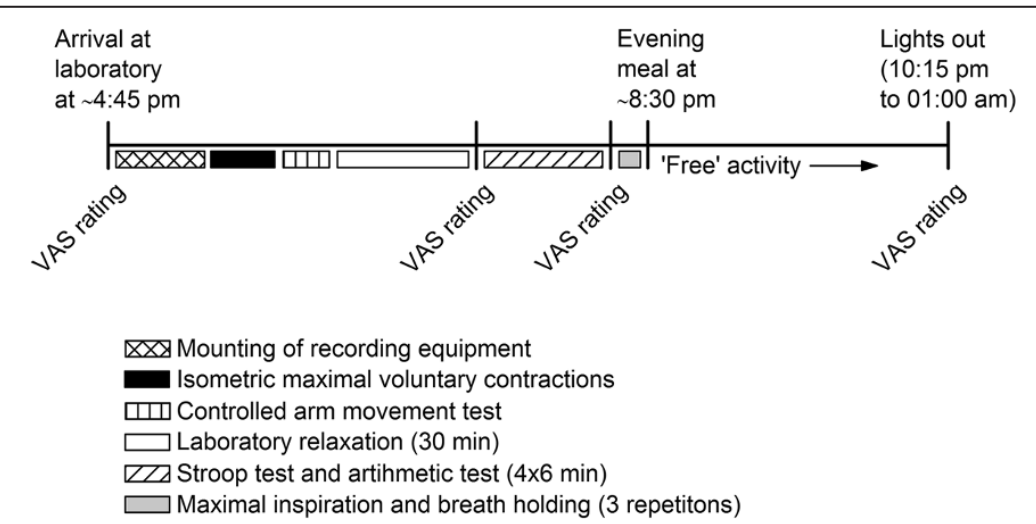

Figure 1 Order and time schedule for the data collection. Recording equipment was mounted immediately after arrival at the laboratory ( 4:45 pm, range 4:30-5:00 pm) followed by an experimental session with laboratory recordings. After an evening meal at $\sim 8: 30$ pm the subjects were free to choose activity until bedtime. sEMG activity (trapezius, deltoideus, and biceps) and heart rate were recorded continuously from start of the experimental session until bedtime. Pain (shoulder/neck, low back), general tension, and perceived stress were scored on Visual Analogue Scale (VAS) at four occasions. 
modified lead II electrocardiogram (ECG), and respiratory frequency by a strain gauge embedded in a flexible belt placed around the chest just below the sternum.

For the ECG recordings, the QRS complex was detected, and the R-R intervals were derived on a beat-bybeat basis to determine heart rate (HR) during the stress test, during Laboratory relaxation in the laboratory, and during the 5-min evening period with lowest trapezius sEMG. Variables indicating heart rate variability (HRV) were determined $[39,40]$. Time domain measures included the standard deviation of the NN interval (SDNN) and the root mean square successive difference (RMSSD), based on 5 -min periods of recordings. SDNN is thought to reflect total variability while RMSSD is mainly thought to reflect vagal modulation of heart activity. In case of the mental stress test and Laboratory relaxation in the laboratory, the second last 5-min period was selected. Frequency domain measures included the power of the low frequency component (LF; 0.04-0.15 Hz) and the high frequency component (HF; 0.15-0.4 Hz), as well as the ratio of the two components of the heart period power spectrum (LF/HF ratio). The recordings were visually inspected for ectopic heart beats and artifacts. Heart beats classified as non-normal beats were excluded from further analysis.

Bipolar sEMG (bar-shaped contact surfaces 1 by $10 \mathrm{~mm}$, $10 \mathrm{~mm}$ spacing between surfaces) was recorded from the clavicular and acromial fibers of the dominant upper trapezius, middle deltoid, and biceps brachii. The midpoint of the acromial trapezius electrode was placed at a point $2 \mathrm{~cm}$ distal to the midpoint of a line from the spinous process of the $7^{\text {th }}$ cervical vertebra $(C 7)$ toward the lateral edge of the acromion [41,42]. The clavicular electrode was placed in parallel to the acromial electrode, $2 \mathrm{~cm}$ in the ventral (clavicular) direction [25]. For the middle deltoid the electrode was placed on a line from the acromion to the lateral epicondyle of the elbow, corresponding to the greatest bulge of the muscle. For the biceps brachii the electrode was placed on the line between the medial acromion and the fossa cubit at $1 / 3$ from the fossa cubit. All signals were sampled at $1 \mathrm{kHz}$. The sEMG signal was band-pass filtered at $10-450 \mathrm{~Hz}$ and root-mean-square (RMS) values were calculated using a $100 \mathrm{~ms}$ non-overlapping window. Three isometric MVCs were performed for each muscle with simultaneous recording of sEMG and force. The highest sEMG response was used to normalize the sEMG signal $\left(\% \mathrm{EMG}_{\max }\right)$. For each $\mathrm{MVC}$, participants were instructed to develop maximal force within 1-2 s and thereafter hold the force for 3-5 s. A 1-min break was applied between each MVC. MVCs for trapezius and middle deltoid were performed with participants in an erect seated posture, with arms $90^{\circ}$ abducted in the scapular plane. Resistance was applied just proximal to the elbow joint by adjustable straps connected to two strain-gauge force transducers secured to the floor. MVCs for the dominant biceps brachii were performed with participants in seated position, elbow flexed at $90^{\circ}$, and the elbow supported against the side of the body. Resistance was applied unilaterally to the dominant arm just proximal to the wrist joint by the adjustable strap that was connected to one of the force transducers. The force signal was low-pass filtered $(10 \mathrm{~Hz}$, Butterworth, $6^{\text {th }}$ order) and downsampled to $10 \mathrm{~Hz}$ before further analysis. Maximal force was determined as the median of the highest $0.5 \mathrm{~s}$ interval (i.e., median of 5 samples) for each MVC. Recordings of FM patients were inspected for indication of systematic force reduction with successive MVCs, but no such effect was found.

Table 2 presents maximal force and $\mathrm{sEMG}_{\max }$ during MVCs. FM patients generated lower force than HC during shoulder abduction (not significant) and elbow flexion. This is an anticipated consequence of their patient status, but may represent a source of error if "true" force capacity of FM patients is masked by sub-maximal force generation in the calibration contractions due to, e.g., pain-associated inhibition. Correlation analyses showed no association of maximal force with indicators of present pain (pain in the laboratory, pain last $24 \mathrm{hrs}$, pain last week). Alternative sEMG calibrations were nevertheless explored by upward adjustment of patient $\mathrm{sEMG} \mathrm{max}_{\max }$ values by $20 \%$ to compensate for group differences in maximal force. sEMG activity during the evening and in tests was quantified by median activity level and by rest time (sEMG amplitude $<0.5 \%$ $\mathrm{EMG}_{\max }$ ) [43].

\section{Questionnaires}

Two questionnaires were administered to assess subjective health complaints and personality traits. The Subjective Health Complaints inventory consists of 29 questions concerning somatic and psychological complaints last 30 days [44]. For each item, severity of the complaint is rated on a 4 -point scale ( $0=$ none, $3=$ severe $)$ and duration by number of days during the last 30 days. The Karolinska Scales of

\section{Table 2 sEMG calibration contractions}

\begin{tabular}{llll}
\hline & FM patients & Controls & $\mathbf{p}^{\mathbf{a}}$ \\
\hline Force $(\mathrm{N})$ & & & \\
Shoulder abduction & $101(37), 41-206$ & $116(21), 61-148$ & 0.08 \\
Elbow flexion & $110(29), 39-167$ & $136(27), 91-201$ & 0.002 \\
sEMG $_{\text {max }}(\mu \mathrm{V})$ & & & \\
Clavicular trapezius & $337(189), 94-711$ & $534(203), 208-879$ & 0.002 \\
Acromial trapezius & $276(163), 87-615$ & $501(298), 119-1257$ & 0.003 \\
Middle deltoid & $217(96), 93-358$ & $315(105), 133-549$ & 0.01 \\
Biceps brachii & $177(81), 54-365$ & $259(131), 67-564$ & 0.01 \\
\hline
\end{tabular}

Maximal force and $\mathrm{sEMG}_{\max }$ during isometric maximal voluntary contractions (i.e., shoulder abduction and elbow flexion) for fibromyalgia (FM) patients and healthy controls.

Values are mean (SD), range.

andependent samples t-test. 
Personality (KSP) is a self-rating questionnaire constructed to measure stable personality traits [45]. KSP consists of 135 items grouped into 15 subscales. Three subscales were used in this study: muscular tension, psychic anxiety, and somatic anxiety. Each item is scored on a 4-point Likert scale $(0=$ does not apply at all, $3=$ applies completely).

Four indexes of potential relevance to influence physiological responses [24] were constructed from items in the two questionnaires: 1) musculoskeletal symptoms (pain in neck, shoulders and upper back, perceived stiffness in upper and lower body), 2) non-musculoskeletal symptoms (irregular HR, hot flushes, headache, abdominal pain, dizziness), 3) cognitive/psychological symptoms (anxiety, forgetfulness, depression), 4) muscle tension (tension in jaw muscles, feeling of tenseness when trying to sleep, difficulty in relaxing). The index scores (average of the included items) were considered long-term traits, to be distinguished from VAS scores of pain, stress, and perceived general tension on the experimental day [27].

\section{Statistical analysis}

The Kolmogorov-Smirnov test was used to explore normality of dependent variables. All HR variables, all symptom indexes, most force variables (three of four), and most sEMG $\mathrm{max}_{\max }$ variables (six of eight) were normally distributed. None of the sEMG variables or VAS-score variables was normally distributed. The independent samples t-test was used to test differences between groups for normally distributed data while the Mann-Whitney U test was used to test group differences for non-normally distributed data. A mixed design repeated measures ANOVA was used to test differences between repeated recordings of HR and HRV. If Mauchly's test indicated violation of sphericity, a Greenhouse-Geisser correction was applied [46]. Friedman's ANOVA was used to test differences between repeated recordings of sEMG and VAS-score variables. Wilcoxon signed-rank test with a Bonferroni correction was used for post-hoc comparisons. Linear regression coefficients and Spearman's $\rho$ were used for correlation analyses. Significance level was set to $\mathrm{p}<0.05$.

\section{Results}

\section{Physiological responses}

Figure 2 shows sEMG responses in the laboratory tests. Clavicular trapezius sEMG activity was significantly higher for FM patients than HCs in sustained inspiration with breath holding (A). Both trapezius responses were markedly higher for FM patients vs. HCs in the mental stress test (C) and in Laboratory relaxation (D). sEMG rest time was correspondingly lower for FM patients (e.g., mental stress test: clavicular trapezius: 14 vs. $75 \%, \mathrm{p}<0.011$; acromial trapezius: 14 vs. $76 \%, \mathrm{p}<0.001)$. Muscle activity during Laboratory relaxation was unchanged, comparing the first and last 5-min interval of the 30-min observation period. Trapezius sEMG activity of FM patients and HCs was similar in the test with dynamic arm movement (B). Statistically significant, but only moderately higher deltoid and biceps responses were observed for FM patients in several of the tests with higher trapezius responses. Downward adjustment of FM patient sEMG responses by $20 \%$ to compensate for putative submaximal effort in the calibration contractions did not alter the statistically significant differences of trapezius responses, comparing FM patients and HCs.

Figure 3 shows sEMG activity for quiet seated activity during the evening (A), for the evening meal (B), and for the 5-min period with lowest upper trapezius sEMG activity (C; always occurring during quiet seated activity). FM patients were not distinguished from $\mathrm{HCs}$ in quiet seated activity and lowest 5-min period, but showed higher trapezius and biceps activity during the evening meal. sEMG rest time during the evening did not distinguish FM patients from HCs (clavicular trapezius: 20 vs. $23 \%$, acromial trapezius 30 vs. $23 \%$; data not shown).

Table 3 presents HR responses. Repeated measures ANOVA showed a significant main effect of condition $(\mathrm{F}=41.1, \mathrm{df}=1.7, \mathrm{p}<0.001)$, but no main group effect $(\mathrm{F}=1.3$, $\mathrm{df}=1, \mathrm{p}=0.25)$, and no interaction between group and condition $(\mathrm{F}=2.3, \mathrm{df}=1.7, \mathrm{p}=0.12)$. Paired statistics showed elevated $\mathrm{HR}$ of FM patients in Laboratory relaxation relative to lowest 5-min during the evening (71 vs. $66 \mathrm{bpm}$ ), and further elevation in the mental stress test (76 bpm; Table 3). $\mathrm{HR}$ of HCs was unchanged in Laboratory relaxation vs. lowest 5-min period during the evening (67 vs. $65 \mathrm{bpm}$ ), and was elevated to the same level as for FM patients in the mental stress test (both groups at $76 \mathrm{bpm}$ ).

HRV analysis showed reduced variability for FM patients by the time domain variables SDNN (main group effect: $F=8.51, \mathrm{df}=1, \mathrm{p}=0.006$; no main effect of condition, no interaction between group and condition) and RMSSD (main group effect: $F=5.05, \mathrm{df}=1, \mathrm{p}=0.03$; main effect of condition: $\mathrm{F}=5.02, \mathrm{df}=1.74, \mathrm{p}=0.012$; no interaction between group and condition). A non-significant tendency of elevated low-frequency HRV of FM patients in the stress test using time domain analysis (i.e., lower RMSSD) was very clear by frequency domain analysis (HF main condition effect: $\mathrm{F}=20,82, \mathrm{df}=1.54, \mathrm{p}<0.001$; LF main condition effect: $\mathrm{F}=16.69, \mathrm{df}=1.63, \mathrm{p}<0.001 ; \mathrm{LF} / \mathrm{HF}$ ratio: $\mathrm{F}=13.43, \mathrm{df}=1.68$, $\mathrm{p}<0.001)$. Conversely, the frequency domain analysis did not show lower HRV for FM patients in the stress test.

\section{Subjective variables and the association to physiological responses}

Shoulder/neck pain of FM patients was relatively high upon arrival in the laboratory, with a non-significant reduction after Laboratory relaxation (Table 4). The stress test provoked a statistically significant increase in shoulder/neck pain that stayed at the same elevated level till bedtime 

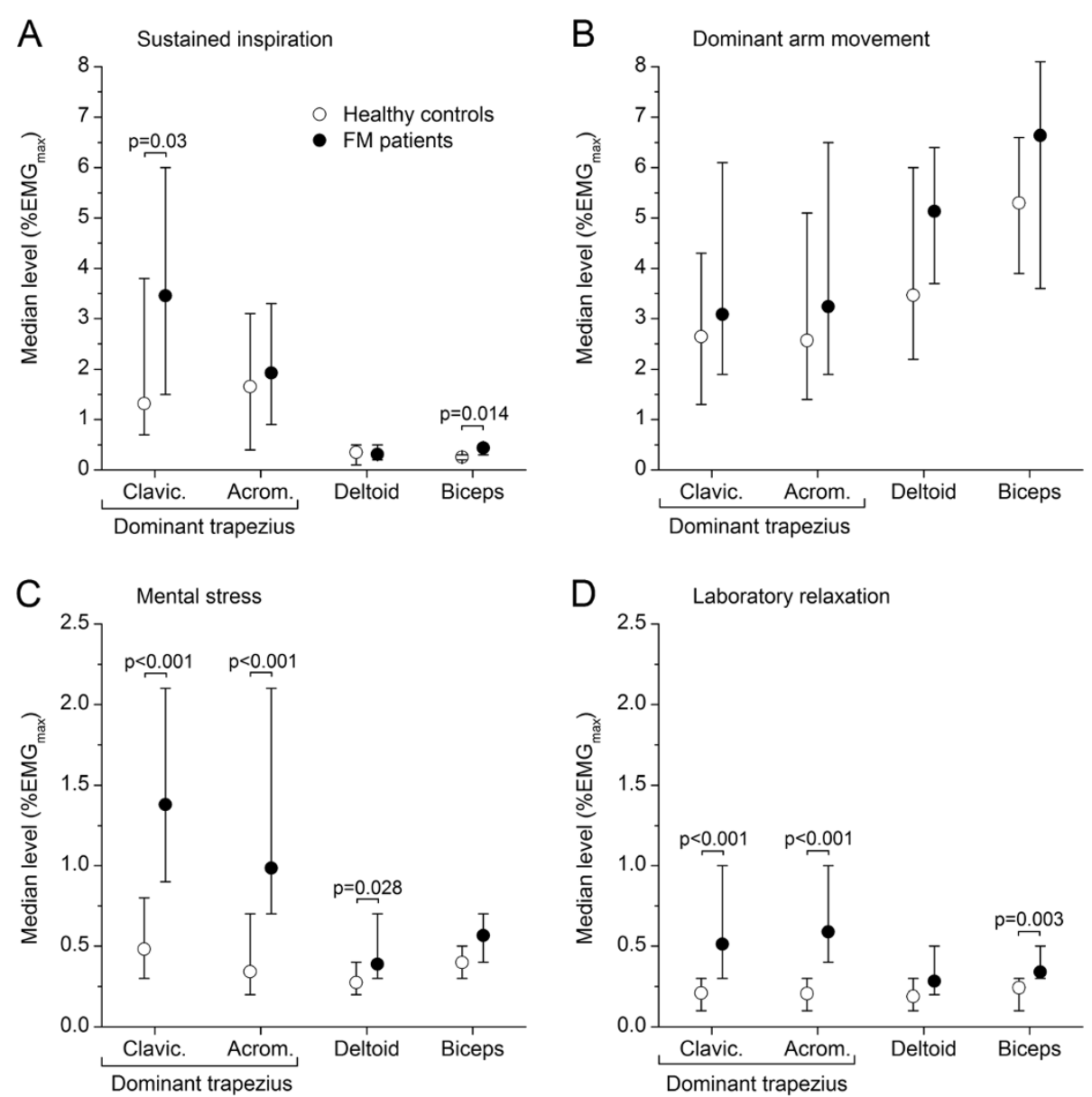

Figure 2 sEMG activity during tests. Median sEMG level (\%EMG $\left.{ }_{\max }\right)$ for clavicular and acromial fibers of dominant trapezius, middle deltoid, and biceps brachii during sympathetic activation, i.e., closing of epiglottis following deep inspiration (A), dominant arm movement (B), mental stress (C), and relaxation in the laboratory (D). Healthy controls (open circles) and fibromyalgia (FM) patients (filled circles) are represented by different symbols. Error bars indicate $95 \% \mathrm{Cl}$ of median.

(38\%, CI: 25-45). Low back pain of FM patients was lower than shoulder/neck pain (significant following Laboratory relaxation), and was unchanged following the stress test. Perceived general tension was higher for FM patients than HCs upon arrival and after Laboratory relaxation, and was elevated and equally high for the two groups following the stress test. FM patients and HCs scored similarly on perceived stressfulness of their day, and effort invested in the stress test.

Most items used to construct the indexes of musculoskeletal symptoms; muscle tension symptoms, nonmusculoskeletal symptoms, and cognitive and psychological symptoms (cf. Methods) were scored significantly higher by FM patients vs. HC. The only significant correlation found between index scores and sEMG activity or HR was a negative correlation between musculoskeletal symptoms and clavicular trapezius activity for FM patients during the stress test $(\mathrm{R}=-.58, \mathrm{p}=0.002)$.

\section{Discussion}

To our knowledge, this is the first study to present data on muscle activity, HR, and HRV of FM patients in an unrestrained field setting to approximate daily living, together with responses to tests with stress exposure and instructed relaxation. Trapezius sEMG activity was higher for FM patients in the mental stress test and in sustained inspiration, which causes a sympathetic activation response [36,37]. FM patients further showed elevated upper trapezius activity in a laboratory rest situation and during the evening meal, the latter result potentially interesting as nutrient intake causes an increase in sympathetic activation $[47,48]$.

FM patients were consistently distinguished from $\mathrm{HCs}$ by higher trapezius activity level in situations that trigger sympathetic activation (inspiratory breath holding, eating, mental stress test), valid for both trapezius electrode placements in most comparisons. A previous study with 

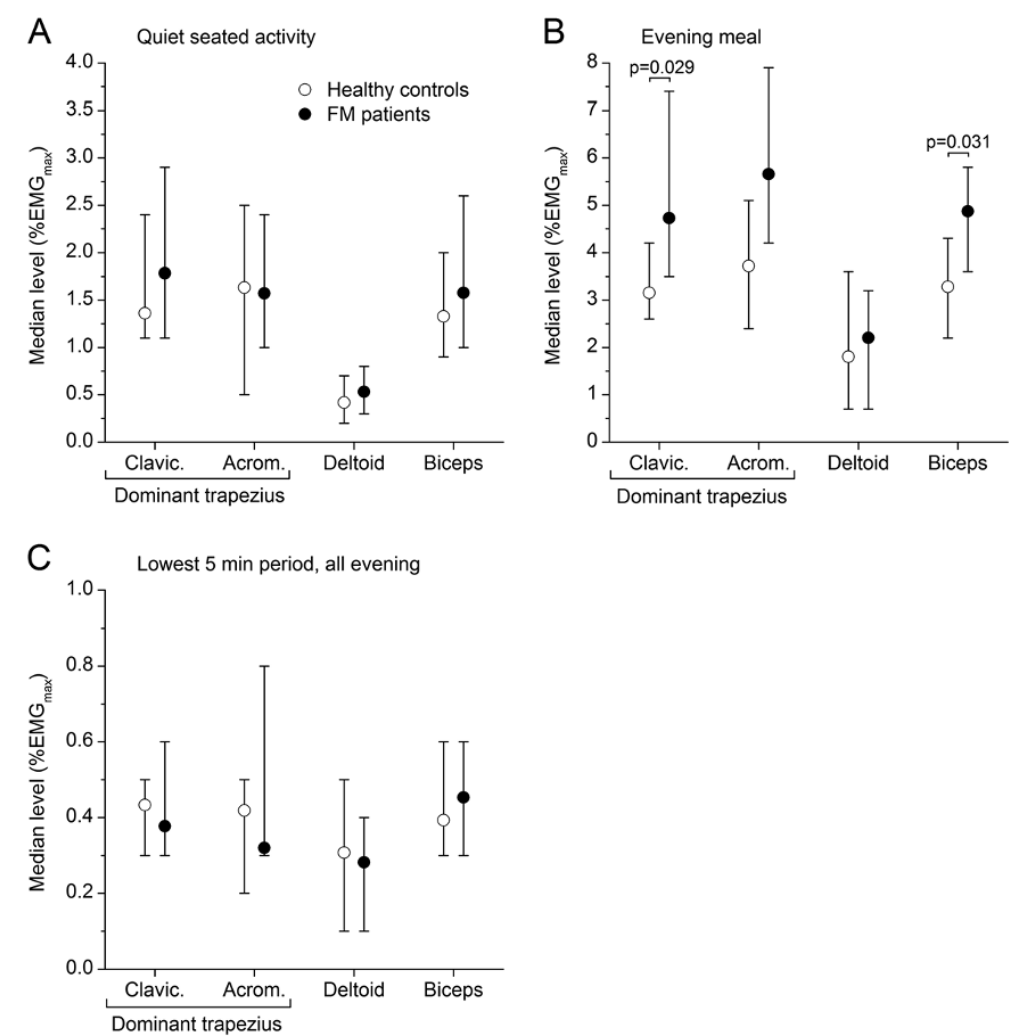

Figure 3 sEMG activity during evening activities. Median SEMG level (\%EMG $\max$ ) for clavicular and acromial fibers of dominant trapezius, middle deltoid, and biceps brachii during quiet seated activity at the patient hotel (A), evening meal (B), and the 5-min period with lowest sEMG activity during the evening (C). Healthy controls (open circles) and fibromyalgia (FM) patients (filled circles) are represented by different symbols. Error bars indicate $95 \% \mathrm{Cl}$ of median.

recording of single trapezius motor units indicated a stressassociated input to trapezius motoneurones [49], potentially representing a distinct pre-motor pathway. FM patients were not distinguished from HC by trapezius sEMG and HR in the 5 min period with trapezius activity at its lowest value in the field setting, when subject were watching TV or reading in their hotel room, or in the test with arm movement. These situations seem unlikely to trigger a sympathetic activation response. FM patients and HCs were

Table 3 Heart rate responses

\begin{tabular}{llll}
\hline & Mental stress & $\begin{array}{l}\text { Laboratory } \\
\text { relaxation }\end{array}$ & $\begin{array}{l}\text { Lowest } \mathbf{5} \text { min, } \\
\text { evening }\end{array}$ \\
\hline FM patients & $76(8), 58-89^{b}$ & $71(8), 55-85^{c}$ & $66(3), 52-78$ \\
Controls & $76(7), 64-88^{d}$ & $67(8), 54-86$ & $65(3), 45-76$ \\
$p^{a}$ & 0.89 & 0.06 & 0.35 \\
\hline
\end{tabular}

Heart rate (bpm) during mental stress test, laboratory relaxation, and 5-min period with lowest heart rate during evening activities for fibromyalgia (FM) patients and healthy controls.

Values are mean $(\mathrm{SD})$, range.

${ }^{a}$ Independent samples t-test; Paired samples t-test: ${ }^{\text {b }}$ different from Laboratory relaxation $(p=0.001)$, and lowest 5 min period during evening $(p<0.001)$; cdifferent from lowest 5 min period during evening $(p=0.009) ;{ }^{d}$ different from Laboratory relaxation $(p<0.001)$ and lowest 5 min period during evening $(p<0.001)$.
Table 4 Subjective scores on Visual Analogue Scale (VAS) of pain (only fibromyalgia [FM] patients) and perceived general tension at arrival, after laboratory relaxation, and after mental stress test for FM patients and healthy controls

\begin{tabular}{lllll}
\hline & Arrival & $\begin{array}{l}\text { Laboratory } \\
\text { relaxation }\end{array}$ & $\begin{array}{l}\text { Mental } \\
\text { stress }\end{array}$ & $\mathbf{p}^{\mathbf{a}}$ \\
\hline Pain within FM group & & & & \\
Shoulder/neck pain & $28(8-45)$ & $22(7-29)$ & $39(28-47)^{\mathrm{c}}$ & $<0.001$ \\
Low back pain & $12(0-25)$ & $7(0-11)$ & $7(0-17)$ & 0.09 \\
$p^{\mathrm{b}}$ & 0.06 & 0.002 & $<0.001$ & \\
General tension & & & & \\
FM patients & $32(13-42)$ & $17(7-25)$ & $52(37-58)^{\mathrm{d}}$ & $<0.001$ \\
Controls & $10(5-24)^{\mathrm{e}}$ & $5(2-8)$ & $40(21-52)^{\mathrm{f}}$ & $<0.001$ \\
$\mathrm{p}^{\mathrm{b}}$ & 0.007 & $<0.001$ & 0.13 & \\
\hline
\end{tabular}

Values are median $(95 \% \mathrm{Cl})$.

${ }^{a}$ Friedman's ANOVA; ${ }^{b}$ Wilcoxon signed rank test; ' different from Laboratory relaxation $(p<0.001) ;{ }^{d}$ different from arrival $(p=0.03)$ and Laboratory relaxation $(p<0.001)$; ${ }^{e}$ different from Laboratory relaxation $(p<0.001)$ and mental stress $(p<0.001){ }^{f}$ different from Laboratory relaxation $(p<0.001)$. 
further differentiated by trapezius activity in the laboratory rest period prior to the stress test. Elevated HR of FM patients in this period compared to the period with low trapezius activity in the evening may indicate a sympathetic activation response, an effect not observed for HCs. A possible explanation of this finding is that FM patients worry about the subsequent stress period and some form of anticipatory stress response is observed. Previous reports of elevated baseline activity and blunted responses of physiological variables with stress exposure, indicative of sympathetic activation, are consistent with this interpretation [50-52].

A previous study of physiological responses and pain development to sustained stress exposure, but using a different stress test, did not distinguish trapezius test responses of FM patients from HCs [20]. An important procedural difference between the two studies is that the previous study reported sEMG responses calibrated in absolute units $(\mu \mathrm{V})$, due to the difficulty of achieving reliable reference contractions of forehead muscles. The large variation in $\mathrm{sEMG}_{\max }$ (cf. Table 2) makes comparisons of sEMG using absolute unit calibration rather insensitive. Many of the statistically significant comparisons in the present material only showed statistical significance by onetailed comparisons when recalculating results using absolute unit calibration. sEMG calibration by MVC or by sub-maximal reference contraction is however the preferred calibration procedure [26]. Stress exposure in the present study furthermore seems stronger as HCs showed markedly higher $\mathrm{HR}(\triangle \mathrm{HR}=9$ vs. $3 \mathrm{bpm}$; [53]) and shoulder/neck pain responses ( 17 vs. 3 VAS units after $30 \mathrm{~min}$ of stress exposure; [20]) than in the previous study. Indeterminate differences in test administration may cause differential sEMG responses if stress level in the test is low $[19,20]$.

FM patients showed systematic lower sEMG responses during MVC (i.e., proportionally larger reduction in sEMG activity than the corresponding reduction in MVC force). This can be an error source or, alternatively, an interesting feature of muscles in this patient group. The reduction of sEMG amplitude in submaximal contractions at a set force level [54] suggests that low sEMG amplitude is a feature of FM patients. Low sEMG of FM patients may be due to disturbed muscle metabolism [10] or synchronization of active motor units [55]. Interstitial potassium is higher in patients with trapezius myalgia [56], potentially lowering muscle fiber action potentials and sEMG, and may occur also for FM patients.

It is debated whether FM represents the end point of a continuum from regional to generalized pain, or is a separate disorder $[1,10,57,58]$. Shoulder/neck pain was the dominant complaint of FM patients upon arrival in the laboratory. Stress exposure caused pain development in shoulder/neck, without influencing (much lower level) low back pain. FM patients were in this respect indistinguishable from patients with trapezius myalgia, favoring the integrated hypothesis on pathophysiological mechanisms. FM patients show muscle pathology [10,59] with clear similarities to muscle pathology in regional shoulder and neck pain [56,60,61]. The interest in muscular and autonomic responses of FM patients is rooted in evidence that peripheral components of the muscular and autonomic systems contribute to pain elicitation, additional to or integrated with CNS-based mechanisms [62]. Upper trapezius activity may not per se induce pain development, since trapezius activity in the stress test is similar to trapezius activity during the evening at the patient hotel and is at a level generally observed in sedentary living [63]. Trapezius activity may alternatively function as a marker of parallel pain-inducing activation responses, such as localized trigger point activity [8,36,64].

The FM patients in this study presented low levels of cortisol [31] and catecholamines [33], indicating downregulation of target organs of both the hypothalamicpituitary-adrenal axis and the sympathetic nervous system. This does not necessarily reflect the activity of central components of the sympathetic system; e.g., pituitary adrenocorticotropic hormone release was up-regulated in FM despite a relative depression of cortisol release [65]. Central components of the autonomic nervous system are clearly biased towards the sympathetic branch in FM, as indicated by low HRV $[40,66]$, which was also observed for FM patients in this study. This may represent a basis for stressassociated upper trapezius activity.

The HRV variables in the frequency domain (LF, HF, LF/ HF ratio; [66]), did not distinguish FM patients from $\mathrm{HC}$, but showed a shift towards LF bias in the stress test, which was not observed with the time-domain variables (RMSSD showed a main effect of condition, no longer significant when FM patients and $\mathrm{HC}$ were analyzed separately). This illustrates that time-domain and frequency-domain variables describing HRV are not strictly comparable, although broadly equivalent $[40,66]$. The combined results show the expected effects of both group and condition on HRV responses: sympathetic bias of FM patients overall, and a shift towards sympathetic bias for both groups upon stress exposure.

The physiological results are consistent with the initial hypothesis; however, large inter-individual variation in responses and the possible influence of experimental conditions (e.g., stress level, experimental setting and circumstances of tests) suggest that the study should still be considered explorative and be replicated in similar study designs to fully understand stress-associated physiological responses of FM patients. It is conceivable that the mounting of recording equipment influence behavior and thus results. However, the long recording period and isolation from their everyday environment would argue against such an effect. Uncontrolled variation in adopted posture may 
contribute to the observed variation in sEMG results. Results on FM patient heterogeneity are reported in view of the interest in this aspect $[24,52]$, but limited material implies low sensitivity of the analysis. A larger study base is required for differentiation of a FM patient population by index variables, but this is a demanding requirement for experimental studies with extensive physiological recording. A meta-analysis of several experimental studies may prove a future opportunity in this respect.

\section{Conclusion}

FM patients in this study show clear evidence of disturbance of the autonomic system. Upper trapezius activity is similar to $\mathrm{HC}$ in unrestrained daily activities, but is enhanced in situations with performance-related and anticipative stress, presumably representing a provocation of the sympathetic nervous system. Generalized pain is a diagnostic criterion for FM; however, shoulder/neck pain dominates at arrival and is the dominant pain response to stress exposure. Similar, presumably peripheral mechanisms of pain elicitation may be associated with stressful experiences both for patients with FM and patients with regional pain in neck and shoulders.

\section{Competing interests}

The authors have no conflicts of interest or competing financial interests to declare.

\section{Authors' contributions}

RHW participated in the design of the study, the collection of data, analysis and interpretation of data, and drafting the manuscript. PJM participated in the design of the study, the collection of data, analysis and interpretation of data, and drafting the manuscript. HWL participated in the design of the study, the collection of data, analysis and interpretation of data, and reviewed the manuscript for intellectual content. RR participated in the design of the study and reviewed the manuscript for intellectual content. UL participated in the design of the study, analysis and interpretation of data, and reviewed the manuscript for intellectual content. All authors read and approved the final manuscript.

\section{Acknowledgements}

This study was supported by the Swedish Research Council. We are grateful to Magne Rø MD and Tonje Okkenhaug Johansen MD for help in the selection and clinical examination of the study participants.

\section{Author details}

'Department of Industrial Economics and Technology Management, Norwegian University of Science and Technology, Trondheim, Norway. ${ }^{2}$ Department of Human Movement Science, Norwegian University of Science and Technology, Trondheim, Norway. ${ }^{3}$ Department of Psychology, Stockholm University, Stockholm, Sweden. ${ }^{4}$ CHESS (Centre for Health Equity Studies), Stockholm University, Stockholm, Sweden.

Received: 7 June 2012 Accepted: 13 March 2013

Published: 18 March 2013

\section{References}

1. Ablin J, Neumann L, Buskila D: Pathogenesis of fibromyalgia: a review. Joint Bone Spine 2008, 75:273-279.

2. Adler GK, Kinsley BT, Hurwitz S, Mossey CJ, Goldenberg DL: Reduced hypothalamic-pituitary and sympathoadrenal responses to hypoglycemia in women with fibromyalgia syndrome. Am J Med 1999, 106:534-543.
3. Adler GK, Manfredsdottir VF, Rackow RM: Hypothalamic-pituitary-adrenal axis function in fibromyalgia and chronic fatigue syndrome.

Endocrinologist 2002, 12:513-524.

4. Cohen H, Neumann L, Shore M, Amir M, Cassuto Y, Buskila D: Autonomic dysfunction in patients with fibromyalgia: application of power spectral analysis of heart rate variability. Semin Arthritis Rheum 2000, 29:217-227.

5. Desmeules JA, Cedraschi C, Rapiti E, Baumgartner E, Finckh A, Cohen P, Dayer $P$, Vischer TL: Neurophysiologic evidence for a central sensitization in patients with fibromyalgia. Arthritis Rheum 2003, 48:1420-1429.

6. Williams DA, Clauw DJ: Understanding fibromyalgia: lessons from the broader pain research community. J Pain 2009, 10:777-791.

7. Vierck CJ: Mechanisms underlying development of spatially distributed chronic pain (fibromyalgia). Pain 2006, 124:242-263.

8. Ge HY, Nie HL, Madeleine P, Danneskiold-Samsøe B, Graven-Nielsen T, Arendt-Nielsen L: Contribution of the local and referred pain from active myofascial trigger points in fibromyalgia syndrome. Pain 2009, 147:233-240.

9. Harth M, Nielson WR: The fibromyalgia tender points: use them or lose them? A brief review of the controversy. J Rheumato/ 2007, 34:914-922.

10. Bengtsson A: The muscle in fibromyalgia. Rheumatol 2002, 41:721-724.

11. Bazzichi L, Dini M, Rossi A, Corbianco S, De Feo F, Giacomelli C, Zirafa C, Ferrari C, Rossi B, Bombardieri S: Muscle modifications in fibromyalgic patients revealed by surface electromyography (SEMG) analysis. BMC Musculoskelet Disord 2009, 10:36.

12. Casale R, Sarzi-Puttini P, Atzeni F, Gazzoni M, Buskila D, Rainoldi A: Central motor control failure in fibromyalgia: a surface electromyography study. BMC Musculoskelet Disord 2009, 10:78.

13. Elert J, Kendall SA, Larsson B, Mansson B, Gerdle B: Chronic pain and difficulty in relaxing postural muscles in patients with fibromyalgia and chronic whiplash associated disorders. J Rheumato/ 2001, 28:1361-1368.

14. Gerdle B, Lemming D, Kristiansen J, Larsson B, Peolsson M, Rosendal L: Biochemical alterations in the trapezius muscle of patients with chronic whiplash associated disorders (WAD) - a microdialysis study. Eur J Pain 2008, 12:82-93.

15. Wærsted M, Westgaard RH: Attention-related muscle activity in different body regions during VDU work with minimal physical activity. Ergonomics 1996, 39:661-676.

16. Clauw DJ, Williams DA: Relationship between stress and pain in workrelated upper extremity disorders: the hidden role of chronic multisymptom illnesses. Am J Ind Med 2002, 41:370-382.

17. Okifuji A, Turk DC: Stress and psychophysiological dysregulation in patients with fibromyalgia syndrome. Appl Psychophysiol Biofeedback 2002, 27:129-141.

18. Sarzi-Puttini P, Atzeni F, Diana A, Doria A, Furlan R: Increased neural sympathetic activation in fibromyalgia syndrome. Ann New York Acad Sci 2006, 1069:109-117.

19. Bansevicius D, Westgaard RH, Stiles T: EMG activity and pain development in fibromyalgia patients exposed to mental stress of long duration. Scand J Rheumatol 2001, 30:92-98.

20. Nilsen KB, Westgaard RH, Stovner LJ, Helde G, Rø M, Sand TH: Pain induced by low-grade stress in patients with fibromyalgia and chronic shoulder/neck pain, relation to surface electromyography. Eur J Pain 2006, 10:615-627.

21. Wærsted M, Bjørklund RA, Westgaard RH: The effect of motivation on shoulder-muscle tension in attention-demanding tasks. Ergonomics 1994, 37:363-376.

22. Thieme K, Turk DC: Heterogenity of psychophysiological stress responses in fibromyalgia syndrome patients. Arthritis Res Ther 2006, 8:R9.

23. Müller W, Schneider EM, Stratz T: The classification of fibromyalgia syndrome. Rheumatol Int 2007, 27:1005-1010.

24. Wilson HD, Robinson JP, Turk DC: Toward the identification of symptom patterns in people with fibromyalgia. Arthritis Rheum 2009, 61:527-534.

25. Jensen $\mathrm{C}$, Westgaard $\mathrm{RH}$ : Functional subdivision of the upper trapezius muscle during low-level activation. Eur J Appl Physiol 1997, 76:335-339.

26. Mathiassen SE, Winkel J, Hägg GM: Normalization of surface EMG amplitude from the upper trapezius muscle in ergonomic studies - A review. J Electromyograph Kinesiol 1995, 5:197-226.

27. Holte KA, Vasseljen O, Westgaard RH: Exploring perceived tension as a response to psychosocial work stress. Scand J Work Environ Health 2003, 29:124-133.

28. Vasseljen O, Holte KA, Westgaard RH: Shoulder and neck complaints in customer relations: individual risk factors and perceived exposures at work. Ergonomics 2001, 44:355-372. 
29. Vasseljen O, Westgaard $\mathrm{RH}$ : A case-control study of trapezius muscleactivity in office and manual workers with shoulder and neck pain and symptom-free controls. Int Arch Occup Environ Health 1995, 67:11-18.

30. Wolfe F, Smythe HA, Yunus MB, Bennett RM, Bombardier C, Goldenberg DL, Tugwell P, Campbell SM, Abeles M, Clark P, Fam AG, Farber SJ, Fiechtner JJ, Franklin CM, Gatter RA, Hamaty D, Lessard J, Lichtbroun AS, Masi AT, Mccain GA, Reynolds WJ, Romano TJ, Russell IJ, Sheon RP: The American College of Rheumatology 1990 criteria for the classification of Fibromyalgia. Arthritis Rheum 1990, 33:160-172.

31. Riva R, Mork PJ, Westgaard RH, Rø M, Lundberg U: Fibromyalgia syndrome is associated with hypocortisolism. Int J Behav Med 2010, 17:223-233.

32. Riva R, Mork PJ, Westgaard RH, Lundberg U: Comparison of the cortisol awakening response in women with shoulder and neck pain and women with fibromyalgia. Psychoneuroendocrinology 2012, 37:299-306.

33. Riva R, Mork PJ, Westgaard RH, Johansen TO, Lundberg U: Catecholamines and heart rate in female fibromyalgia patients. J Psychosom Res 2012, 72:51-57.

34. Mork PJ, Nilsson J, Lorås HW, Riva R, Lundberg U, Westgaard RH: Heart rate variability in fibromyalgia patients and healthy controls during non-REM and REM sleep: a case-control study. Scandinavian Journal of Reumatology 2013. in press.

35. Lundberg U, Kadefors R, Melin B, Palmerud G, Hassmen P, Engström M, Dohns IE: Psychophysiological stress and EMG activity of the trapezius muscle. Int J Behav Med 1994, 1:354-370.

36. Chung JW, Ohrbach R, Mccall WD: Effect of increased sympathetic activity on electrical activity from myofascial painful areas. Am J Phys Med Rehabil 2004, 83:842-850.

37. Macefield VG, Wallin BG: Effects of static lung-inflation on sympathetic activity in human muscle nerves at rest and during asphyxia. J Auton Nerv Syst 1995, 53:148-156.

38. Westgaard RH, Bjørklund R: Generation of muscle tension additional to postural muscle load. Ergonomics 1987, 30:911-923.

39. Stein PK, Bosner MS, Kleiger RE, Conger BM: Heart rate variability: a measure of cardiac autonomic tone. Am Heart J 1994, 127:1376-1381.

40. Berntson GG, Bigger JT, Eckberg DL, Grossman P, Kaufmann PG, Malik M Nagaraja HN, Porges SW, Saul JP, Stone PH, Van der Molen MW: Heart rate variability: origins, methods, and interpretive caveats. Psychophysiology 1997, 34:623-648.

41. Jensen C, Vasseljen $\mathrm{O}$, Westgaard $\mathrm{RH}$ : The influence of electrode position on bipolar surface electromyogram recordings of the upper trapezius muscle. Eur J Appl Physiol 1993, 67:266-273.

42. Jensen C, Vasseljen O, Westgaard RH: Estimating maximal EMG amplitude for the trapezius muscle: on the optimization of experimental procedure and electrode placement for improved reliability and increased signal amplitude. J Electromyograph Kinesiol 1996, 6:51-58.

43. Mork PJ, Westgaard RH: Low-amplitude trapezius activity in work and leisure and the relation to shoulder and neck pain. J Appl Physio/ 2006, 100:1142-1149.

44. Eriksen HR, Ihlebæk C, Ursin H: A scoring system for subjective health complaints (SHC). Scand J Public Health 1999, 27:63-72.

45. Schalling D, Edman G: Personality and vulnerability to psychopathology: the development of the Karolinska Scales of Personality (KSP). Stockholm, Sweden: Karolinska Institutet; 1987.

46. Field A: Discovering statistics using SPSS. London: SAGE Publications Ltd; 2005.

47. Fagius J, Berne C: The increase in sympathetic nerve activity after glucose ingestion is reduced in type I diabetes. Clin Sci 2000, 98:627-632.

48. Landsberg L: A teleological view of obesity, diabetes and hypertension. Clin Exp Pharmacol Physiol 2006, 33:863-867.

49. Westgaard RH, Bonato $P$, Westad C: Respiratory and stress-induced activation of low-threshold motor units in the human trapezius muscle. Exp Brain Res 2006, 175:689-701.

50. Cohen H, Neumann L, Alhosshle A, Kotler M, Abu-Shakra M, Buskila D: Abnormal sympathovagal balance in men with fibromyalgia. J Rheumatol 2001, 28:581-589.

51. Furlan R, Colombo S, Perego F, Atzeni F, Diana A, Barbic F, Porta A, Pace F, Malliani A, Sarzi-Puttini P: Abnormalities of cardiovascular neural control and reduced orthostatic tolerance in patients with primary fibromyalgia. J Rheumatol 2005, 32:1787-1793.

52. Kanbara K, Fukunaga M, Mutsuura H, Takeuchi H, Kitamura K, Nakai Y: An exploratory study of subgrouping of patients with functional somatic syndrome based on the psychophysiological stress response: its relationship with moods and subjective variables. Psychosom Med 2007, 69:158-165.
53. Nilsen KB, Sand T, Westgaard RH, Stovner LJ, White LR, Leistad RB, Helde G, $\mathrm{R} \varnothing \mathrm{M}$ : Autonomic activation and pain in response to low-grade mental stress in fibromyalgia and shoulder/neck pain patients. Eur J Pain 2007, 11:743-755

54. Falla D, Andersen H, Danneskiold-Samsøe B, Arendt-Nielsen L, Farina D: Adaptations of upper trapezius muscle activity during sustained contractions in women with fibromyalgia. J Electromyograph Kinesiol 2010, 20:457-464.

55. Farina D, Merletti R, Enoka RM: The extraction of neural strategies from the surface EMG. J Appl Physiol 2004, 96:1486-1495.

56. Rosendal L, Kristiansen J, Gerdle B, Søgaard K, Peolsson M, Kjær M, Sørensen J, Larsson B: Increased levels of interstitial potassium but normal levels of muscle IL-6 and LDH in patients with trapezius myalgia. Pain 2005, 119:201-209.

57. Schweinhardt P, Sauro KM, Bushnell MC: Fibromyalgia: a disorder of the brain? Neuroscientist 2008, 14:415-421.

58. Wolfe F: Fibromyalgianess. Arthritis Rheum 2009, 61:715-716.

59. Le Goff P: Is fibromyalgia a muscle disorder? Joint Bone Spine 2006, 73:239-242.

60. Andersen LL, Suetta C, Andersen JL, Kjær M, Sjøgaard G: Increased proportion of megafibers in chronically painful muscles. Pain 2008, 139:588-593.

61. Rosendal L, Larsson B, Kristiansen J, Peolsson M, Søgaard K, Kjær M, Sørensen J, Gerdle B: Increase in muscle nociceptive substances and anaerobic metabolism in patients with trapezius myalgia: microdialysis in rest and during exercise. Pain 2004, 112:324-334.

62. Staud R, Nagel S, Robinson ME, Price DD: Enhanced central pain processing of fibromyalgia patients is maintained by muscle afferent input: a randomized, double-blind, placebo-controlled study. Pain 2009, 145:96-104.

63. Mork PJ, Westgaard RH: Long-term electromyographic activity in upper trapezius and low back muscles of women with moderate physical activity. J Appl Physiol 2005, 99:570-578.

64. Simons DG, Hong CZ, Simons LS: Endplate potentials are common to midfiber myofacial trigger points. Am J Phys Med Rehabil 2002, 81:212-222.

65. Griep E, Boersma J, de Kloet E: Altered reactivity of the hypothalamicpituitary-adrenal axis in the primary fibromyalgia syndrome. J Rheumatol 1993, 20:469-474.

66. Malik M, Bigger JT, Camm AJ, Kleiger RE, Malliani A, Moss AJ, Schwartz PJ: Heart rate variability: standards of measurement, physiological interpretation, and clinical use. Eur Heart J 1996, 17:354-381.

doi:10.1186/1471-2474-14-97

Cite this article as: Westgaard et al:: Trapezius activity of fibromyalgia patients is enhanced in stressful situations, but is similar to healthy controls in a quiet naturalistic setting: a case-control study. BMC Musculoskeletal Disorders 2013 14:97.

\section{Submit your next manuscript to BioMed Central and take full advantage of:}

- Convenient online submission

- Thorough peer review

- No space constraints or color figure charges

- Immediate publication on acceptance

- Inclusion in PubMed, CAS, Scopus and Google Scholar

- Research which is freely available for redistribution 